\title{
DERECHOS SOCIALES Y COMUNIDADES AUTÓNOMAS *
}

\author{
Ignacio TORRES MURO \\ Catedrático de Derecho Constitucional UCM \\ Del Cuerpo de Letrados del Tribunal Constitucional \\ igtorres@pdi.ucm.es
}

\begin{abstract}
RESUMEN
El estudio pretende analizar críticamente la proliferación de los derechos llamados sociales en los Estatutos de Autonomía recientemente aprobados en España. Se intenta encontrar una explicación al fenómeno, poniéndolo en relación con las aspiraciones de las diferentes Comunidades Autónomas, su implicación en las diferentes politicas sociales y las pretensiones de construir entidades similares al Estado central y dotadas, por tanto, de instrumentos pseudoconstitucionales.
\end{abstract}

Palabras clave: derechos sociales, Comunidades Autónomas, Estatutos de Autonomía, Estado central.

\section{ABSTRACT}

The study seeks critically to analyze the proliferation of so-called social rights in the Statutes of Autonomy passed recently in Spain. It attempts to find an explanation for the phenomenon, relating it to the aspirations of the different Autonomous Communities, their involvement in the different social policies, and the attempts to create entities similar to the central State, and having, therefore, pseudo-constitutional instruments.

Keywords: social rights, Autonomous Communities, Statutes of Autonomy, central State.

* El texto que se presenta aquí es una reelaboración del que se expuso en el V Encuentro hispano-italiano de constitucionalistas católicos, celebrado en Milán del 31 de marzo al 1 de abril de 2011, sobre el tema «Diritti sociali e regionalismo in Spagna ed in Italia». Ha sido corregido para la publicación añadiendo el aparato bibliográfico correspondiente y ampliando de manera notable diversas argumentaciones, pero aún conserva las licencias propias de su carácter oral, que deberá disculpar el lector. También habrá de tenerse en cuenta su condición en algunos casos divulgativa, dado el público en parte italiano al que estaba destinado originalmente. Sirva el mismo para agradecer a Antonio Torres del Moral, infatigable trabajador y agudo constitucionalista, los muchos años que ha dedicado al cultivo de esta ciencia. Lo ha hecho con capacidad crítica, acierto y seriedad, y sólo con un trabajo que se pretende crítico y serio podía yo participar modestamente en su homenaje. 


\section{ZUSAMMENFASSUNG}

Der Aufsatz untersucht kritisch die Ausbreitung der sogenannten Sozialrechte in den Statuten der Autonomen Gemeinschaften, die kürzlich in Spanien verabschiedet wurden. Es wird versucht, eine Erklärung für das Phänomen zu finden, indem die Absichten der verschiedenen Autonomen Gemeinschaften - ibr Engagement bei den verschiedenen Sozialpolitiken - sowie ibr Ziel, gleichartige soziale Institutionen zu schaffen wie die des Zentralstaats, zueinander in Beziehung gesetzt werden. Der Autor kommt zu dem Schluss, dass diese geschaffenen Institutionen mit pseudoverfassungsrechtlichen Instrumenten ausgestattet werden.

Schlüsselwörter: Sozialrechte, Autonome Gemeinschaften, Statuten der Autonomen Gemeinschaften, Zentralstaat.

SUMARIO: I. INTRODUCCIÓN.-II. DERECHOS SOCIALES Y REGIONALISMO.-III. DERECHOS SOCIALES Y ESTATUTOS.-IV. LOS DERECHOS SOCIALES EN EL ESTADO AUTONÓMICO.-V. LA POSTURA DEL TRIBUNAL CONSTITUCIONAL.-VI. GARANTÍAS.-VII. CONCLUSIÓN.

\section{INTRODUCCIÓN}

Debo, ante todo, agradecer a los organizadores de este encuentro que hayan pensado en mí para realizar esta relación introductoria al debate sobre derechos sociales y regionalismo, más aún cuando no he escrito demasiado ni sobre derechos sociales ni sobre el Estado autonómico español, temas ambos sobre los que tengo una opinión bastante crítica, no tanto a sus formulaciones teóricas como a sus realizaciones prácticas, opinión crítica que se reflejará en lo que sigue.

El punto de partida de mi exposición serán dos afirmaciones incontrovertibles. Por un lado la de que, pese a lo que les pese a los neoliberales furibundos, que de todo hay, España es un ejemplo de Estado social ${ }^{1}$,

${ }^{1}$ Sobre el Estado social en la Constitución puede remitirse, de toda la extensa bibliografía, a A. Fernández-MirANDA CAMPOAmor, «El Estado social», en Revista Española de Derecho Constitucional, núm. 69, 2003, pp. 130-180. Para comprender los problemas de la relación entre este tipo de Estado y nuestro peculiar modelo de descentralización es imprescindible J. J. SolozÁbal Echavarría, «El Estado social como Estado autonómico», en Teoría y realidad constitucional, núm. 3, 1999, pp. 61-78. Son interesantes en este terreno las aportaciones a M. A. APARICIO (coord.), Derechos constitucionales y formas políticas. Actas del Congreso sobre derechos constitucionales y Estado autonómico, Barcelona, Cedecs, 2001. En especial, en clave comparada, J. WoeHRLING, «Etats composes et droits constitutionnalises...», pp. 315 y ss., y S. GAMBINO, «Stato regionale e diritti sociali: l'esperienza italiana nella prospectiva comparatistica», pp. 361 y ss. También es un ejercicio de comparación España/Canadá el libro de J. M. Castellá Andreu y S. Grammond (coords.), Diversidad, 
cicatero y todavía en construcción si se compara con otros Estados sociales europeos, pero Estado social al fin y al cabo. La Constitución lo proclama con claridad en su art. 1.1 («España se constituye en un Estado social»).

Esto no es de extrañar. En el momento en el que se elabora nuestro texto constitucional (1978) los Estados sociales son una realidad consolidada en toda Europa, esa Europa en la que los españoles pretendíamos integrarnos. Es verdad que empezaba ya a hablarse de la crisis del Estado social, pero para nosotros el problema no era tanto revisarlo como empezar a construirlo, y de ahí la enfática proclamación constitucional que, pasados unos años, se ve con nostalgia.

Como existe un Estado social, en España se ha dado también un reconocimiento de los llamados derechos sociales, la mayoría en los arts. 39 y ss. CE, bajo el epígrafe de «Principios rectores de la política social y económica», pero también en otros sectores de la declaración de derechos del texto constitucional [derecho al trabajo (art. 35), a la negociación colectiva (art. 37) y a adoptar medidas de conflicto colectivo (art. 37), entre los «Derechos y deberes de los ciudadanos»], incluso entre los protegidos de una manera más contundente con el recurso de amparo ante el Tribunal Constitucional y la reserva de ley orgánica [a la educación (art. 27), a sindicarse (art. 28) y a la huelga (art. 28), entre los «Derechos fundamentales y las libertades públicas»].

Cerrando, por tanto, esta primera afirmación de base, puede decirse que el Estado español es un Estado social con un amplio y generoso reconocimiento de los derechos sociales en el nivel constitucional, hasta el punto de que se ha hablado de excesos regulativos al decir que nos hallamos ante «normas finalistas de protección jurídica sumamente dificultosa» y que su ordenación es «realmente confusa [...] en parte debida precisamente a su desmesurada extensión». Por ejemplo, lo ha hecho De Otto, que no era precisamente un liberalote ${ }^{2}$.

derechos fundamentales y federalismo. Un diálogo entre Canadá y España, Barcelona, Atelier, 2010. Sobre el tema en España M. A. García HerRera, «Los derechos sociales en el Estado autonómico», en M. A. ApARICIO (coord.), Derechos constitucionales y formas políticas..., op. cit., pp. 405 y ss. Y, sobre todo, R. CANOSA UsERA, Derechos sociales y principios rectores en los Estatutos de Autonomía. El modelo autonómico de Estado social, a publicar en el libro homenaje al profesor Jorge de Esteban. También tiene interés P. ReQuEjo RodRíguEz, «La articulación de los derechos sociales en el Estado autonómico», en M. A. PRESNO LiNERA y I. W. SARLET (eds.), Los derechos sociales como instrumento de emancipación, Cizur Menor, Thomson-Aranzadi, 2010, pp. 63 y ss.

2 Vid. I. DE OTTO, Derecho constitucional. Sistema de fuentes, Barcelona, Ariel, 1987. Las citas están tomadas de la p. 32. 
El segundo punto de partida es el de que España es un Estado fuertemente descentralizado. Desde el relativo fracaso del intento de meter en cintura a las Comunidades Autónomas, que supusieron los Pactos Autonómicos de 1981 como consecuencia del fallo del Tribunal Constitucional sobre la Ley Orgánica de Armonización del Proceso Autonómico (STC 76/1983, de 5 de agosto), a las consecuencias de los Pactos de los años noventa, que ampliaron las competencias de las Comunidades Autónomas, el proceso, que conoce sus últimas expresiones en las reformas de los Estatutos de Autonomía aprobadas a partir del año 2006, es un proceso de continuada ampliación de los poderes de aquéllas, ampliación firmemente apoyada por una jurisprudencia constitucional que no dudaría en calificar de proautonomista ${ }^{3}$.

Todos estos factores han hecho que, a la altura de 2011, España se presente como una nación fuertemente descentralizada, y que, aunque se hayan alzado voces en el sentido de frenar este proceso, el mismo aparece como difícilmente reversible.

Esta conclusión, que se puede predicar en general del Estado autonómico español, es aún más llamativa en el terreno que nos ocupa, el de los derechos sociales, en el que el protagonismo de las Comunidades Autónomas no se puede discutir, por más que el Estado conserve algunas competencias de coordinación y regulación legislativa ${ }^{4}$.

\section{DERECHOS SOCIALES Y REGIONALISMO}

A partir de esos dos presupuestos puede uno adentrarse en el tema de nuestro encuentro - derechos sociales y regionalismo-. He de advertiros, sin embargo, que cuando Josep María Castellá contactó conmigo para invitarme a hablar aquí me propuso hacerlo sobre «Derechos y Estatutos de Autonomía», o al menos así lo entendí yo, probablemente mal. El caso es que durante un par de meses desarrollé mi trabajo sobre este segundo asunto, de modo que, cuando pude ver que el tema se circunscribía a

3 Vid. la síntesis de la misma que hasta 2005 se hace en G. FERNÁndez FARREREs, La contribución del Tribunal Constitucional al Estado autonómico, Madrid, Iustel, 2005.

${ }^{4}$ Por poner un ejemplo de análisis del funcionamiento del reparto de competencias referido a unos derechos sociales de especial importancia, puede remitirse a E. SAENZ RoYO, «Derechos de protección social y Estado autonómico: los márgenes constitucionales de actuación del Estado y de las CCAA», en A. EmBID IRUjo (dir.), Derechos económicos y sociales, Madrid, Iustel, 2009, pp. 25 y ss. 
los derechos sociales y se conectaba con el regionalismo en general, decidí cambiar la orientación de mis investigaciones. Pero sólo pude hacerlo de una manera limitada, por las dificultades de extenderlas más allá de los Estatutos de Autonomía.

De modo que, aun reconociendo que hay problemas de derechos sociales fuera de los Estatutos de las Comunidades Autónomas, dado que los mismos son tratados muchas veces en el nivel de la legislación autonómica, o, incluso, de los reglamentos procedentes del poder ejecutivo, voy a centrarme en cómo se abordan los derechos sociales en las normas institucionales básicas de nuestras nacionalidades y regiones.

\section{DERECHOS SOCIALES Y ESTATUTOS}

Para empezar con las afirmaciones críticas debo decir que me cuento entre quienes ven con recelo la inclusión en los Estatutos de Autonomía de un amplio reconocimiento de los derechos en general ${ }^{5}$, y de los derechos sociales en particular.

En mi edición del año 1999 del texto de los Estatutos de Autonomía entonces vigentes firmé un estudio preliminar en el que hablaba de «delirios calificables como de grandeza si no fuera ésta una afirmación un poco dura» ${ }^{6}$, en referencia a la inclusión en aquellos textos de algunas, muy pocas, normas programáticas o de reconocimiento de derechos. Podéis imaginaros cuál ha sido mi reacción ante la generosidad en estos temas de los Estatutos aprobados a partir de $2006^{7}$. Una cierta estupefacción y una

${ }^{5}$ En la polémica de Díez-Picazo con Caamaño me inclino por dar la razón al primero. Vid. L. M. Díez-Picazo Giménez, «¿Pueden los Estatutos de Autonomía declarar derechos, deberes y principos?», en Revista Española de Derecho Constitucional, núm. 78, 2006, pp. 63 y ss.; F. CAAMaÑo Domínguez, «Sí, pueden (declaraciones de derechos y Estatutos de Autonomía)», en Revista Española de Derecho Constitucional, núm. 79, 2007, pp. 33 y ss., y L. M. DíEz-PiCAZo, «De nuevo sobre las declaraciones estatutarias de derechos: respuesta a Francisco Caamaño», en Revista Española de Derecho Constitucional, núm. 81, 2007, pp. 63 y ss.

${ }^{6}$ I. Torres Muro, «Estudio Preliminar», en I. Torres Muro (ed.), Los Estatutos de Autonomía, Madrid, Centro de Estudios Políticos y Constitucionales, 1999, p. 40.

${ }^{7}$ Un análisis del problema en el primer Estatuto de esta nueva tanda puede verse en J. F. Mestre Delgado, «Los derechos de los valencianos reconocidos en el Estatuto», en J. M. Baño León (dir.), Comentario al Estatuto de Autonomía de la Comunidad Valenciana, Cizur Menor, Thomson-Civitas, 2007, pp. 91 y ss. En general, el problema ha dado lugar a una amplia bibliografía de la que pueden destacarse, sin ánimo de exhaustividad, los siguientes trabajos: M. Aparicio Wilhelmi y G. Pisarello Prados, «El reconocimiento de derechos, deberes y principios en los Estatutos de Autonomía...», en El Clip, núm. 42, 
postura muy crítica ante una realidad que se alejaba, por la vía del «engorde», de mi ideal del Estatuto limitado a los contenidos del art. 147 CE y poco más, siempre con base en la Constitución.

Sigo creyendo que esto ha sido un error que creará problemas en el futuro, o, al menos, más problemas de los que resuelve. He sometido estas soluciones a una crítica muy dura en un texto que no llegó a publicarse, titulado significativamente «El engorde de los Estatutos de Autonomía» ${ }^{8}$, en el que ponía en solfa lo que jocandi causa mi maestro Alfonso Fernández-Miranda llama el alma de Constitución y el cuerpo de reglamento de los nuevos Estatutos; es decir, argumento yo, que, por un lado, pretenden emular en su ámbito a lo que normalmente entendemos por norma suprema, y, por otro, son de un grado de detalle impropio de un conjunto de reglas de este tipo, por definición dedicadas a ocuparse de los fundamentos de un orden jurídico, y no de aspectos más propios de las de menor rango.

Nos encontramos, por un lado, con su intención de cumplir labores «semiconstitucionales» ${ }^{9}$. Pero, además, de una «semiconstitución» entendida en el sentido de documento programático que constriñe claramente al legislador democrático, en una tradición que resumió bien en su momento nuestro colega portugués Gomes Canoltilho ${ }^{10}$ y que ha encontrado su máxima expresión en algunos textos latinoamericanos.

Para el profesor de Coimbra, esa Constitución de tipo «dirigente» «marca una decisiva distancia en relación al entendimiento de la política

Barcelona, Institut d'Estudis Autonòmics, 2007; C. Rosado VILlaverde, «Los derechos en los Estatutos de Autonomía...», en Revista General de Derecho Público Comparado, núm. 3, 2008; A. Català i Bas, «La inclusión de una carta de derechos en los Estatutos de Autonomía», en Revista Española de la Función Consultiva, núm. 4, 2005, pp. 181 y ss.; R. CANOSA UsERA, «La declaración de derechos en los nuevos Estatutos de Autonomía», en Teoría y Realidad Constitucional, núm. 20, 2007, pp. 61 y ss.; M. CARRILlo, «Los derechos, un contenido constitucional de los Estatutos de Autonomía», en Revista Española de Derecho Constitucional, núm. 80, 2007, pp. 49 y ss.; F. BALAGUER CALLEJÓN, «Derechos, principios y objetivos en los Estatutos de Autonomía reformados», en Anuario Jurídico de La Rioja, núm. 13, 2008, pp. 11 y ss., y E. Expósito, «La regulación de los derechos en los nuevos Estatutos de Autonomía», en Revista d'Estudis Autonomics i Federals, núm. 5, 2007, pp. 147 y ss.

8 «El engorde de los Estatutos de Autonomía» (junio de 2008), texto inédito del que en este trabajo se aprovechan partes sustanciales.

9 Sobre los temas que se van a abordar a continuación debe verse S. MuÑoz Machado, «El mito del Estatuto-Constitución», 2004, extraído el 16 de enero de 2012 de www.idpbarcelona.net/docs.public/iccaa/2004. En especial cuando habla de «ideología del Estatuto constitucional» (p. 1) y «el mito de que el proceso estatutario no se distingue del todo del proceso constituyente» (p. 2).

${ }^{10}$ J. J. Gomes Canotilho, Constituçao dirigente e vinculaçao do legislador. Contributo para a compreensao das normas constitucionais programáticas, Coimbra, Coimbra Editora, 1982. 
como dominio jurídicamente libre y constitucionalmente desvinculado: la vinculación jurídico-constitucional de los actos de dirección política no es ya una vinculación a través de límites, sino una verdadera vinculación material que exige un fundamento constitucional para esos mismos actos» ${ }^{11}$, y además aspira «a la modificación de la sociedad a través del derecho» ${ }^{12}$. Nada que ver con un sano concepto liberal de Constitución, que no parece estar en la agenda de nuestros reformadores de Estatutos de Autonomía.

Dichas labores semiconstitucionales se cumplen con la previsión generosa de derechos, deberes y principios rectores (por ejemplo, arts. 11-16 del Estatuto de Castilla y León). Es decir, la previsión de directrices que deberá seguir el legislador autonómico, porque así lo ha querido el legislador estatuyente, que hay que recordar que es legislador estatal, puesto que, aunque se dé una significativa participación en el proceso legislativo de los órganos de las Comunidades Autónomas, los Estatutos de Autonomía se aprueban mediante ley orgánica (art. $81 \mathrm{CE}$ ).

Y, por otro lado, en esa esquizofrenia que caracteriza a los nuevos Estatutos, tienen cuerpo de reglamento; esto es, descienden a unos detalles impropios de una norma con pretensiones de generalidad. Dejando a un lado la regulación de las competencias, que ahora no nos interesa, se puede poner de nuevo el ejemplo del Estatuto de Autonomía de Castilla y León, en el que se reconoce, valga la muestra [art. 13.2.b)], el derecho a la regulación de plazos para que les sea aplicado a los ciudadanos un tratamiento médico. La técnica normativa no puede ser más discutible, si de un Estatuto de Autonomía estamos hablando.

No debe pensarse que esta desmesurada extensión de los Estatutos de Autonomía es algo producto del capricho de un legislador estatal que ha colaborado conscientemente en dar cancha a las aspiraciones de las fuerzas políticas autonómicas. No nos engañemos. Detrás del fenómeno hay toda una estrategia muy bien diseñada, y que tiene unos objetivos muy claros, sintetizados en la necesidad de reinventar el Estado autonómico español.

Resultaría imposible analizar, dentro de los límites de este artículo, todos los aspectos en los que las normas estatutarias de última generación suponen, o aspiran a suponer, cambios profundos en nuestro sistema constitucional, de modo que cabe simplemente referirse a lo que más arriba hemos llamado «aspiración constitucional», y al intento de fijar exhaustivamente en

${ }^{11}$ Ibid., p. 487.

${ }^{12}$ Ibid., p. 488. 
los Estatutos, hasta unos extremos paradójicamente impropios de una norma que tiene las aspiraciones que acabo de señalar, la distribución de competencias, apoyándose en técnicas que blinden las facultades de las Comunidades Autónomas correspondientes, y a hacerlo con tal grado de detalle que se dota a todo el sistema de una rigidez absolutamente impropia de uno en el que se respete algo el principio de lealtad constitucional, base de toda descentralización que pretenda funcionar con ciertas dosis de agilidad.

Lo grave, y perdón por este rodeo dedicado a generalidades antes de abordar el objeto de nuestro estudio, es que parece que estos Estatutos de tipo «dirigente» —en el sentido al que nos hemos referido más arriba siguiendo a Gomes Canotilho- son unas normas que pretenden conformar un programa de actuación a cumplir por el legislador autonómico, programa que se formula, a veces, con un grado de detalle tal que recuerda, pido disculpas por la comparación, a los textos pseudoconstitucionales de los gloriosamente fenecidos, en casi todos los casos, países del llamado socialismo real. Parece como si toda una generación de juristas formados en la visión marxista de la vida, y que vieron frustradas sus aspiraciones, primero, por la dura realidad del franquismo, y luego, por el carácter demoliberal de las soluciones constitucionales de la democracia española, se hubiesen hecho con las riendas del cambio jurídico en las Comunidades Autónomas, y estuvieran imponiendo sus puntos de vista propios de una izquierda que muestra una insospechada lozanía.

Maldades aparte, no es posible descartar totalmente que en el caso de las declaraciones de derechos nos encontremos ante verdaderas necesidades de las Comunidades Autónomas, porque, al fin y a la postre, lo que hay en todas estas nuevas regulaciones es una respuesta a los deseos de los representantes de los ciudadanos de las nacionalidades y regiones, y quizás también de esos ciudadanos, aunque los índices de participación en determinados procesos referendarios inviten a sostener que mucho interés no parecen tener en estos cambios. La opción es una opción más, perfectamente respetable. El problema es que tiene unas importantes consecuencias para el sistema jurídico en su conjunto, y, sobre todo, para el de cada una de las Comunidades Autónomas, consecuencias que, a nuestro juicio, son ciertamente indeseables.

Los efectos perversos de estas soluciones son dos: por un lado, el exceso de límites para el legislador autonómico, dada la funesta combinación de rigidez y complejidad de las normas estatutarias; por otro, la complicación para todo el ordenamiento que supone que una ley de este tipo sea un conjunto de preceptos farragosos y excesivamente detallados. 
En cuanto al primer problema, puede recuperarse aquí, dado que ante un fenómeno semiconstitucional nos encontramos, todo el debate sobre si es necesario imponer límites al legislador democrático en los documentos constitucionales o si los mismos han de ser vistos siempre con sospecha.

No hace falta irse al extremo de cierta doctrina británica — que ve a las Constituciones escritas como un freno antidemocrático a los deseos de unos Parlamentos que son los que verdaderamente están conectados con la voluntad popular, y que, por tanto, es mucho mejor, para el constitucionalismo, no tener documentos de este tipo que impongan la voluntad de sus redactores a las generaciones futuras - para recordar que el carácter antimayoritario de las Constituciones, sobre todo cuando tienen un contenido extenso y prolijo, puede hacer de las mismas un estorbo para quien en cada momento ostente el apoyo del electorado.

Que esa condición de estorbo sea deseable para asegurar ciertos valores, derechos y principios frente a los caprichos de la mayoría, cautela que la historia ha demostrado que es, a veces, muy necesaria, no quiere decir que la misma no resulte en muchas ocasiones excesiva, sobre todo cuando los mecanismos de reforma constitucional pueden convertir a un documento de este tipo en uno muy rígido, o incluso pétreo.

Trasladando esta reflexión general, susceptible evidentemente de muchos mayores desarrollos que los que aquí se han alcanzado, al terreno de las relaciones Estatuto de Autonomía-legislador (o ley) autonómicos, nos encontramos con que aquél, cabeza del ordenamiento correspondiente, lo sabemos, y dotado de una fuerte rigidez, como lo demuestra el análisis de sus normas de reforma, supone un corsé a las actividades del correspondiente Parlamento, corsé que puede resultar adecuado cuando estemos ante una norma estatutaria breve, que se dedique a las tareas que ya dijimos que tenía atribuidas en el diseño constitucional originario, tal y como se ha interpretado hasta ahora, y sea un buen instrument of government, en el sentido anglosajón, pero que podría resultar insoportable cuando lo que manejemos sea un Estatuto que pretenda regular exhaustivamente todos los aspectos de la vida de una Comunidad Autónoma. Entonces, las Cámaras se encontrarían en la posición de meros ejecutores de las políticas ya predeterminadas y sin suficiente margen de acción para responder a nuevas necesidades, o al cambio de orientación en los deseos del electorado.

Los Parlamentos autonómicos no tienen por qué ver restringida su capacidad de actuación por unas regulaciones de las que lo menos que se puede decir es que resultan pretenciosas y producto de una ideología intervencionista hasta extremos preocupantes, que no conduce más que 
a encorsetar la actividad de unos poderes públicos que ya tienen bastante con atender a las necesidades sociales con un presupuesto siempre escaso, y que está claro que deben tener límites en la misma, pero sólo los estrictamente imprescindibles, los que sirvan a intereses preferentes de la comunidad, no a las pretensiones de regular desde la cuna a la tumba la vida de unos ciudadanos que tienen razones para sospechar siempre de los intentos de este tipo.

Nos hallamos con un problema con el que tendremos que convivir en el futuro, de modo que más nos vale a los leguleyos irnos adaptando a este nuevo estado de cosas, caracterizado por una rigidez y una complejidad dignas de mejores causas. No hay que olvidar, sin embargo, que la realidad es muy tozuda y que, dado que estos cambios afectan a organizaciones muy consolidadas, probablemente nos encontremos con algunas resistencias numantinas que no van a facilitar precisamente el funcionamiento del sistema.

Las reflexiones, un tanto amargas, que pueden hacerse, tienen que ver con el sacrificio en el altar de la oportunidad política, y de la lucha también política de regate corto, de principios que siempre han facilitado la solución de los problemas que plantean los ordenamientos complejos, como el español. Nos hallamos ahora ante una realidad cada vez más embrollada, y ello sin que probablemente sea necesario para el servicio a los ciudadanos, que son el último destinatario de las actividades que en el marco del Estado autonómico desarrollan los diversos poderes públicos. Más parece que la clase política —estatal y de las Comunidades Autónomas- se encuentre en el estado superior de una lucha sin cuartel por acaparar poder que, desgraciadamente, lleva muchos años desarrollándose, y que no deja de ser un fenómeno humano y, por tanto, comprensible.

El problema es que la misma amenaza con llevarse por delante unas pautas, algunas de ellas constitucionalmente protegidas, que es necesario preservar si no se quiere que, a medio o largo plazo, nos encontremos con una crisis institucional grave.

Dicho esto, hay que recordar también que la crítica que formulamos es una crítica de oportunidad, que no de constitucionalidad, entre otras cosas porque el Tribunal Constitucional español — Roma locuta, causa finita - ha admitido en sus Sentencias 247/2007, de 12 de diciembre, sobre el Estatuto valenciano, y 31/2010, de 28 de junio, sobre el catalán, que junto al contenido necesario de los Estatutos de Autonomía hay un contenido posible, incluyendo en este último, en teoría, casi cualquier capricho del legislador estatutario, siempre que guarde una conexión, que, leí- 
dos los argumentos del órgano de garantías constitucionales, puede ser tan remota como se quiera, con las competencias de la Comunidad Autónoma correspondiente.

Conviene citar algunos extractos de los fundamentos jurídicos $4 .^{\circ}$ al $7 .^{\circ}$ de esta última decisión para que pueda verse cuál ha sido la postura del Alto Tribunal ante la ampliación desmesurada de los contenidos de los Estatutos. El TC empieza por decir que «la Constitución no determina expresamente cuál ha de ser el contenido posible de un Estatuto de Autonomía». Inmediatamente cita su Sentencia 247/2007, de 12 de diciembre, en el sentido de que «el contenido constitucionalmente lícito de los Estatutos de Autonomía incluye tanto el que la Constitución prevé de forma expresa [...] como el contenido que, aun no estando expresamente señalado por la Constitución, es complemento adecuado por su conexión con las aludidas previsiones constitucionales, adecuación que ha de entenderse referida a la función que en sentido estricto la Constitución encomienda a los Estatutos, en cuanto norma institucional básica que ha de llevar a cabo la regulación funcional, institucional y competencial de cada Comunidad Autónoma».

Pero no deja de poner límites a esa concepción «maximalista» (FJ 6. ${ }^{\circ}$ ). Fundamentalmente dos: uno de orden cuantitativo, «toda vez que la especial rigidez del Estatuto de Autonomía supone una petrificación de su contenido que puede llegar a no compadecerse con un efectivo derecho a la participación política en el ejercicio de los poderes estatuidos», desde el momento en que «ha de partirse del principio de que la reversibilidad de las decisiones normativas es inherente a la idea de democracia, siendo excepcional la exclusión del debate político de determinadas cuestiones que, por afectar al fundamento mismo del sistema, sólo se hacen accesibles a voluntades conformadas en procedimientos agravados y con mayorías cualificadas»; otros de orden cualitativo, que se derivan de la diferencia entre Constitución y Estatutos, básicamente «los que afectan a la definición de las categorías y conceptos constitucionales, entre ellos la definición de la competencia que como acto de soberanía sólo corresponde a la Constitución».

Además del respeto que nos merecen estos pronunciamientos del Tribunal Constitucional, tampoco pretendemos sustituir en el juicio de oportunidad a quien constitucionalmente tiene atribuido el monopolio del mismo, que es el legislador estatutario. Cabe recordar siempre, con el TC, que los Estatutos de Autonomía también son obra del legislador democrático (SSTC 247/2007, de 12 de diciembre, FJ 6. ${ }^{\circ}$, y 31/2010, de 28 de junio, FJ 6. ${ }^{\circ}$ ) Solo queremos decir que, en nuestra opinión, se ha equivocado gravemente. 
De una manera paradójica, de eso que consideramos un error vamos a extraer los materiales para continuar con nuestra exposición, centrada ya en los derechos sociales en los Estatutos de Autonomía y, en general, en el Estado autonómico español.

\section{LOS DERECHOS SOCIALES EN EL ESTADO AUTONÓMICO}

El punto de partida deben ser unas reflexiones sobre el reparto de competencias, en estas materias, en el ordenamiento constitucional español. Sabido es que la CE contiene una lista de materias reservadas al Estado en el art. 149.1. Allí son llamativamente pocas las que tienen que ver con los derechos sociales. Si no hemos hecho mal nuestro repaso podría decirse que, aparte de la transversal de «regulación de las condiciones básicas que garanticen la igualdad de todos los españoles en el ejercicio de los derechos y en el cumplimiento de los deberes constitucionales» (art. 149.1.1. ${ }^{a}$ ), el Estado tiene competencias en inmigración (art. 149.1.2. ${ }^{a}$ ), legislación laboral (art. 149.1.7. ${ }^{a}$ ), bases y coordinación general de la sanidad (art. 149.1.16. ${ }^{a}$ ), legislación básica y régimen económico de la Seguridad Social (art. 149.1.17. ${ }^{a}$ ), asuntos culturales (art. 149.1.28. ${ }^{a}$ y 149.2), y normas básicas para el desarrollo del art. 27 CE (derecho a la educación y libertad de enseñanza, art. 149.1.30.a).

Tomando como ejemplo el Estatuto de Cataluña, dado que, como se sabe, las competencias de las Comunidades Autónomas se fijan en los Estatutos, vemos en su Título IV que se asumen poderes en consumo (art. 123); cooperativas y economía social (art. 124); cultura (art. 127); educación (art. 131); deporte y tiempo libre (art. 134); vivienda (art. 137); inmigración (art. 138); juego y espectáculos (art. 141); juventud (art. 142); medioambiente (art. 144); urbanismo (art. 149); políticas de género (art. 149); protección de datos (art. 156); relaciones con las entidades religiosas (art. 161); sanidad (art. 162); seguridad social (art. 165); servicios sociales, voluntariado, menores y promoción de las familias (art. 166); trabajo y relaciones laborales (art. 170), y universidades (art. 172).

Como vemos, salvo alguna intervención estatal en competencias de legislación o bases, la mayoría de las políticas sociales están en manos de la Generalitat catalana, y, quizás en menor grado, eso sí, algo muy parecido sucede en el resto de las Comunidades Autónomas.

La justificación de la inclusión de derechos sociales en los Estatutos de Autonomía es precisamente la de dotar a esos textos de unas directri- 
ces generales que deberán respetar los poderes públicos autonómicos en el ejercicio de este amplio abanico de competencias. Tiene su lógica pensar que, si damos a esos órganos unos amplios poderes sobre los ciudadanos, pudiera resultar conveniente marcarles unas pautas que en ningún caso podrán traspasar, y ésa parece ser la intención de las declaraciones de derechos y las formulaciones de principios de actuación que se contienen en España en los Estatutos más recientes.

Por no seguir poniendo el acento en el caso catalán ${ }^{13}$, fijémonos ahora en el de Castilla y León ${ }^{14}$, región en la que no está de más recordar que gobierna desde hace años el centro-derecha y que el Estatuto fue fruto de un acuerdo entre el Partido Popular, de esa orientación, y el PSOE. Su Estatuto tiene un Título I («Derechos y principios rectores») ${ }^{15}$ en el que, tras un capítulo de disposiciones generales, se abordan en el segundo los derechos de los castellanos y leoneses distinguiendo los de participación en los asuntos públicos (art. 11), el derecho a una buena Administración (art. 12), los derechos sociales (art. 13, con diez apartados) y el derecho a la no discriminación por razón de género (art. 14). Tras recoger los deberes de los castellanos y leoneses (Capítulo III), en el Capítulo IV, art. 16, se marcan nada menos que veinticinco objetivos que van desde la prestación de unos servicios públicos de calidad (1) a

${ }_{13}$ Sobre este problema en el Estatuto catalán pueden verse las aportaciones recogidas en VVAA, Derechos, deberes y principios en el nuevo Estatuto de Autonomía de Cataluña, Madrid, CEPC, 2006.

${ }^{14}$ Se pueden poner otros ejemplos de los Estatutos reformados a partir de 2006. Así, la LO 1/2007, de 27 de febrero, de reforma del Estatuto de Autonomía de las Illes Balears, contiene un Título II (arts. 13-29) dedicado a los «Derechos, los deberes y las libertades de los ciudadanos de las Illes Balears». El Título I (arts. 11-31) de la LO 5/2007, de 20 de abril, de reforma del Estatuto de Autonomía de Aragón, se ocupa de los «Derechos y principios rectores». La LO 2/2007, de 19 de marzo, de reforma del Estatuto de Autonomía para Andalucía, contiene un Título I (arts. 12 al 41) de «Derechos sociales, deberes y políticas públicas». Por fin, la LO 1/2006, de 10 de abril, de reforma de la LO 5/1982, de 1 de julio, del Estatuto de Autonomía de la Comunidad Valenciana, tiene un Título II (arts. 8-19) que se ocupa de los derechos de los valencianos y valencianas. Una revisión académica de casi todas estas realidades con artículos sobre los derechos en los diferentes Estatutos en M. A. Aparicio (ed.), J. M. Castellá y E. Expósito (coords.), Derechos y principios rectores en los Estatutos de Autonomía, Barcelona, Atelier, 2008.

15 Puede verse el completo análisis contenido en I. Saez Hidalgo y F. Rey Martínez (dirs.), Comentarios al Estatuto de Autonomía de Castilla y León, Cizur Menor, Junta de Castilla y León-Civitas-Thomson, 2011, especialmente las pp. 105-224, con colaboraciones de S. A. Bello Paredes, C. Vidal Fueyo, O. Sánchez Muñoz, F. J. Matía Portilla, E. Seijas Villadangos, I. García Vitoria y L. E. Delgado del Rincón. De interés también F. J. MATía PORTILla, «¿Un Estatuto paraconstitucional? Consenso, nación histórica y declaración de derechos», en Revista Jurídica de Castilla y León, núm. 17, 2009. 
la promoción de la cultura de la paz (25), pasando por la garantía efectiva del derecho a vivir en un medioambiente ecológicamente equilibrado y saludable (15).

Alguien ha hablado, con ironía, de exuberancia latinoamericana ${ }^{16}$, con cierta razón, pero también con cierta injusticia, porque la exuberancia no es monopolio de esa zona del planeta, sino una enfermedad que afecta a juristas vacuos de todos los confines del mundo. El panorama es desolador si comparamos la verborrea incontrolada de las Constituciones de muchos países, también los latinoamericanos, con la durísima realidad en la que se asientan, y que evidentemente no son capaces de modificar. También debo decir que creo bastante poco en las capacidades transformadoras de textos que se convierten en el minuto uno en papel mojado. Sólo desde un simplismo impresentable puede sostenerse que basta con poner negro sobre blanco algunos principios más o menos rimbombantes para que cambien unas realidades que suelen ser muy tozudas.

Se cuenta ${ }^{17}$ que un viajero francés de esos ilustrados que encontraban excitante el exotismo español llegó a un pueblo no excesivamente rico, como casi todos los españoles en el siglo XIX, y vio en la plaza principal, sobre un edificio particularmente sólido, un rótulo que decía «Plaza de la Constitución». Su reflexión amarga fue que eso era una Constitución en España, un poco de yeso sobre granito.

Mucho han cambiado las cosas, pero corremos el riesgo de que esas enfáticas declaraciones estatutarias se queden en eso: en meras colecciones de buenas palabras, que embellecen un texto legislativo, pero que no penetran en un tejido social que es el que es, y ello más aún en unas circunstancias de crisis y recortes en el sector público que no son precisamente las más favorables para la plena realización de tan píos deseos. Pueden cum-

${ }^{16}$ Creo habérselo oído a Victor Ferreres, pero cuando he ido a buscar el dato concreto no lo he encontrado. En todo caso, si no es exacta, la expresión es significativa y una buena descripción de ciertas realidades.

${ }^{17} \mathrm{La}$ anécdota la conocí por primera vez al leer L. SÁnCHEZ AgESTA, Historia del constitucionalismo español (1808-1936), 4. ${ }^{a}$ ed. revisada y ampliada, Madrid, Centro de Estudios Constitucionales, 1984, en donde se recoge en las pp. 21 y 22. Luego fui a la fuente original que es Th. Gautier, Viaje por España, Barcelona, Taifa, 1985. En el sugerente prólogo de M. VÁzQuez Montalbán no se aclara el dato de la fecha del original francés. El viaje lo inició Th. Gautier en mayo de 1840, según su propio testimonio (p. 15). Nada más llegar a Irún escribe: «En un antiguo palacio, convertido en casa comunal, vimos por primera vez la placa de yeso blanco que deshonra otros muchos viejos palacios con la inscripción: Plaza de la Constitución. Lo que encierran las cosas tiene que salir por algún lado: no podría elegirse un símbolo mejor para representar el estado actual del país. Una constitución sobre España es una pellada de yeso sobre granito» (p. 33). 
plir propósitos propagandísticos, pero entonces cabe preguntarnos sinceramente si estamos para propagandas.

Lo más llamativo, además, es que hay honrosas excepciones a esta tendencia. Son las que representan el nuevo Estatuto de Autonomía de Extremadura (LO 1/2011, de 28 de enero) y la reforma de la Ley Orgánica de Reintegración y Amejoramiento del Régimen Foral de Navarra (LO 7/2010, de 27 de octubre).

En el caso del primero no deja de haber cierta tendencia a explayarse, porque se contiene en el mismo un art. 7 que enumera nada menos que veinte principios rectores de los poderes públicos extremeños, dotados de una cierta vacuidad y rimbombancia, que llevan a hablar, por poner dos ejemplos, de que dichos poderes públicos «(7) perseguirán un modelo de desarrollo sostenible y cuidarán de la preservación y mejora de la calidad medioambiental y la biodiversidad de la región, con especial atención a sus ecosistemas característicos, como la dehesa. Asimismo, sus políticas contribuirán proporcionadamente a los objetivos establecidos en los acuerdos internacionales sobre lucha contra el cambio climático», y «(20) entienden como una exigencia ética colectiva, la contribución activa de la sociedad regional y de sus instituciones a la paz y al desarrollo socioeconómico, político y cultural de todas las naciones y pueblos del mundo, mediante sus propias acciones de cooperación al desarrollo y su participación en las que realicen otras instancias españolas o internacionales».

No nos cabe duda de que el barítono de Luisa Fernanda, famosa Zarzuela del siglo pasado, podrá seguir cantando que en su tierra extremeña tiene un nido de amores, tales son los niveles de bondad que destilan los objetivos de los poderes públicos extremeños en su Estatuto.

Pero esta norma no nos interesa por esto, sino porque, contra lo que ha sucedido en otros, en el Estatuto extremeño el tema de los derechos y deberes de los habitantes de esta región se resuelve no con una tabla de los mismos, sino con un art. 6 especialmente comedido, porque nos dice que: «1. Los derechos fundamentales de los extremeños son los establecidos en la Constitución. Además, podrán ejercer frente a los poderes públicos regionales aquellos otros derechos contenidos en este Estatuto o en la legislación, especialmente el de participar en los asuntos públicos directamente o por medio de representantes, y el de petición. 2. Para contribuir al bienestar colectivo, son deberes de los extremeños los previstos en la Constitución y en el resto del ordenamiento jurídico».

Como se ha dicho, parece haber un «evidente deseo del poder estatuyente: los derechos esenciales de los extremeños deben identifi- 
carse claramente, sin ningún tipo de interferencia, con los derechos constitucionales» ${ }^{18}$. Deseo expresado en los debates en el Pleno de la Asamblea de Extremadura por el portavoz socialista, don Ignacio Sánchez Amor, al decir, primero, que «la opción de no tener una carta de derechos es una opción política, una opción política ratificada desde el momento en que el Tribunal Constitucional dijo en la sentencia de la Comunidad Valenciana ${ }^{19}$ que aunque los Estatutos hablen de derechos hay que entenderlos como principios. Pues bien, si son principios, pongámoslos como principios», y segundo, que «los derechos de los extremeños se debatirán aquí, con las opciones de cada mayoría, y el derecho al testamento vital nacerá en esta Asamblea; no se trata de hurtarles a los extremeños derechos, sino que esos derechos formen parte de las posibilidades que les ofrezcan las distintas mayorías parlamentarias, los distintos gobiernos o los distintos partidos en sus programas. Por tanto, estamos ampliando el juego de las mayorías y de la democracia al no incluir una carta de derechos en el Estatuto» ${ }^{20}$.

En el caso de la reforma de la Ley Orgánica navarra, que ya hemos citado, la situación es incluso más llamativa si tenemos en cuenta que la misma se aprueba en plena fiebre de incorporación a los Estatutos de declaraciones de derechos. En la versión de 2010 de la Reintegración y Amejoramiento del Régimen Foral de dicha región solamente nos encontramos con un artículo respecto a estos temas (el 6), artículo que se limita a disponer que «los navarros tendrán los mismos derechos, libertades y deberes fundamentales que los demás españoles».

No hay ni una declaración de derechos, ni unos objetivos para los distintos poderes públicos, nada que se parezca a los excesos regulativos de otras normas de este tipo. Lo verdaderamente trascendente es que eso no supone en absoluto que la Comunidad Foral Navarra esté en una peor situación en cuanto a la existencia de políticas sociales especialmente avanzadas. Ni mucho menos. Más bien todo lo contrario. Esta región se encuentra en primera línea en estas materias, con una legislación social de gran importancia y una actividad de desarrollo de políticas, igualmente sociales, de primer orden. Simplemente, no se ha considerado necesario complicar una Ley de Amejoramiento que en la práctica se limita a prever las compe-

18 V. Álvarez García, «El Estatuto de Autonomía de Extremadura: una visión de conjunto», en V. Álvarez García, Cinco estudios sobre el nuevo Estatuto de Autonomía de Estremadura, Madrid, Iustel, 2012, p. 19.

19 Véase más abajo en este estudio lo que ha dicho el TC.

${ }^{20}$ Citado por V. Álvarez García, op. cit., nota 19, p. 20. 
tencias de la Comunidad y a establecer el régimen de las instituciones de autogobierno: es decir, nuestro ideal de Estatuto de Autonomía.

El caso navarro es un buen ejemplo de cómo se pueden mantener y desarrollar políticas sociales importantes sin necesidad de hacer declaraciones más o menos grandilocuentes, o vacías, en la norma institucional básica. Basta que exista una legislación de desarrollo adecuada y un compromiso efectivo de los poderes públicos de llevar a cabo aquéllas.

Se pueden poner varios casos, en el Derecho constitucional comparado, de Estados con importantes realidades en estas materias que no tienen tablas de derechos sociales. Estados verdaderamente sociales, como, por fijarnos en el quizás más extremo, el Reino Unido. Allí no existe, ni mucho menos, una declaración de derechos de este tipo con rango constitucional, pero de lo que no cabe duda es que hay todo un entramado de prestaciones que puede llevar, sin duda, a que se hable del mismo como un supuesto claro de Welfare State.

\section{LA POSTURA DEL TRIBUNAL CONSTITUCIONAL}

Cabe ahora preguntarnos cuál ha sido la actitud del Tribunal Constitucional ante lo que consideramos excesos de los Estatutos de reciente aprobación en las sentencias en las que se ha ocupado del problema. La palabra correcta, a mi juicio, sería devaluación. Se ha producido un frenazo en seco a los excesos y los entusiasmos, sin por ello dejar de reconocer cierto valor a las declaraciones estatutarias de todo tipo. Ha contribuido decisivamente el Tribunal Constitucional, en sus decisiones más significativas sobre la materia, a desinflar las aspiraciones autonomistas y a poner las cosas en un justo término, que creemos que es el adecuado, una vez que el legislador ha hecho lo que ha hecho.

En la STC 247/2007, de 12 de diciembre (Estatuto valenciano) ${ }^{21}$, se dice (FJ 15):«En conclusión, los Estatutos de Autonomía, que en el ámbito institucional del contenido estatutario pueden establecer derechos subjetivos por sí mismos, en el ámbito de atribución competencial requieren de la colaboración del legislador autonómico, de tal manera que las prescripciones estatutarias relativas a este último ámbito, cualquiera que sea el

${ }^{21}$ Sobre esta sentencia, y en las materias que nos interesan, T. DE LA QUADRA-SALCEDO JANINI, «El régimen jurídico de los derechos sociales estatutarios. Reflexiones tras la STC 247/2007», en Revista General de Derecho Constitucional, núm. 5, 2008, pp. 1 y ss. 
modo literal en que se enuncien, han de entenderse, según antes se acaba de decir, como mandatos, orientaciones u objetivos, dirigidos a los poderes públicos autonómicos para el ejercicio de competencias que el Estado atribuye».

Luego para el Tribunal Constitucional los derechos sociales reconocidos en los Estatutos no son, en ningún caso, derechos subjetivos, sino meros mandatos al legislador autonómico, lo que no es poco, pero es, desde luego, menos de lo que se pretendía.

En la STC 31/2010, de 28 de junio (Estatuto de Cataluña), se insiste en estas ideas, y en su FJ 16 se elaboran más. En primer término, para el Tribunal Constitucional: «Derechos fundamentales son, estrictamente, aquellos que, en garantía de la libertad y de la igualdad, vinculan a todos los legisladores [...] sin excepción. Esa función limitativa sólo puede realizarse desde la norma común y superior a todos los legisladores, es decir, desde la Constitución [...] (los derechos serían fundamentales) [...] por venir proclamados en la norma que es expresión de la voluntad constituyente». Conclusión: solamente son derechos fundamentales los proclamados por la Constitución. Primer jarro de agua fría para determinadas pretensiones.

En segundo lugar, y en el mismo fundamento, se razona que «los derechos reconocidos en Estatutos de Autonomía han de ser, por tanto, cosa distinta. Concretamente derechos que sólo vinculen al legislador autonómico [...] y derechos, además, materialmente vinculados al ámbito competencial propio de la Comunidad Autónoma». Otro freno a las expansiones normativas de determinados Estatutos.

En tercero, se llega a decir que «bajo la misma categoría "derecho" pueden comprenderse realidades normativas muy distintas», entre las que se encuentran los «mandatos de actuación a los poderes públicos», y «este tipo de derechos estatutarios, que no son derechos subjetivos, sino mandatos a los poderes públicos (STC 247/2007, FFJ 13-15), operan técnicamente como pautas (prescriptivas o directivas, según los casos) para el ejercicio de las competencias autonómicas». Ésa es la calificación que se hace de los derechos sociales contenidos en el Estatuto que se enjuicia: ni son derechos fundamentales, ni son verdaderos derechos públicos subjetivos.

Además (FJ 17), se niega que el Estatuto de Autonomía pueda cumplir la función de desarrollo de los derechos fundamentales, reservada a las leyes orgánicas ex art. 81 CE. No es su tarea, y si la ejerciera podría darse «una pluralidad de regímenes de derechos fundamentales (tantos como 
Estatutos), lo que afectaría al principio de igualdad de los españoles en materia de derechos fundamentales». Tampoco puede regular el ejercicio de los mismos, tarea reservada a la ley ordinaria.

Se rechaza, por tanto, expresamente que fuera de la Constitución puedan proclamarse derechos fundamentales, y aunque parece que alguna puerta se deja abierta a la existencia de verdaderos derechos subjetivos estatutarios, no es el campo propio de los derechos sociales, porque la regla general para el Tribunal Constitucional es que no estamos ante auténticos derechos de este tipo.

Resulta curioso como esta doctrina recuerda a la tradicional del Tribunal Supremo, reafirmada en los primeros compases del régimen constitucional, de que las normas constitucionales eran meras normas programáticas. La misma fue corregida por el Tribunal Constitucional con cierta dureza, pero ahora parece retomarla para aproximarse a unas declaraciones de los Estatutos que, desde luego, tienen la confesada pretensión de configurar verdaderos derechos.

\section{GARANTÍAS}

Esta devaluación de los derechos sociales estatutarios nos conduce derechamente al problema de su garantía. En el nivel nacional la mayoría de los derechos sociales sólo podrán ser alegados ante la jurisdicción de acuerdo con las leyes que los desarrollen (art. 53 CE), pero en algunos de los nuevos Estatutos parecía existir la pretensión de que fueran alegables ante los tribunales ordinarios.

Por ejemplo, en Cataluña, con el llamado «amparo catalán» (art. 38.2 de su Estatuto de Autonomía). Dicha pretensión ha venido a desinflarse desde el momento en que el Tribunal Constitucional ha recordado (STC 31/2010, de 28 de junio, FJ 27) que la competencia para regular vías judiciales está reservada a la Ley Orgánica del Poder Judicial y a la legislación procesal del Estado. Las expresiones han sido respetuosas, pero tajantes, ya que en la sentencia citada se dice que hay que tener presente que «los términos concretos en que esa genérica condición (la del Tribunal Superior de Justicia como órgano jurisdiccional al que corresponden funciones de protección de derechos subjetivos estatutarios, aclaramos nosotros) ha de concretarse para el caso de los derechos estatutarios serán, en definitiva, los que resulten de "los procedimientos establecidos en las leyes”, que obviamente sólo pueden ser las del Estado». 
Tampoco resulta fácil configurar un control de «estatutoriedad» (adecuación al Estatuto) de la legislación autonómica. Se intentó, de nuevo, en el Estatuto catalán, atribuyendo la competencia al Consejo de Garantías Estatutarias (art. 76.4) ${ }^{22}$ mediante una especie de control previo vinculante, que el Tribunal Constitucional, celoso de sus competencias, ha declarado contrario a la norma suprema (STC 31/2010, FJ 32), porque, si se entiende como un control previo al desarrollo del procedimiento legislativo, «supondría una inadmisible limitación de la autoridad y las competencias parlamentarias, con grave quebranto de los derechos de participación política», y si es uno inmediatamente anterior a la publicación de la norma, se perjudicaría «el monopolio de rechazo de las normas con fuerza de ley reservado por el art. $161 \mathrm{CE}$ al TC». En ambos casos nos encontramos con una normativa anticonstitucional.

De todos modos, el propio Tribunal Constitucional español sí que podría vigilar esa adecuación de la legislación autonómica a los Estatutos, en cuanto que norma jerárquicamente superior y cabecera de los diferentes ordenamientos de las Comunidades Autónomas, pero, dado que estamos hablando de normas con rango de ley, ese órgano es el único que puede hacerlo.

Otro supuesto es el de la aplicación directa por los tribunales ordinarios de una norma estatutaria que reconociera un derecho social. Puede servirnos de ejemplo del posible régimen el art. 39 del Estatuto de Autonomía de Andalucía ${ }^{23}$ que afirma que «los actos de los poderes públicos de la Comunidad que vulneren los derechos mencionados en el artículo anterior (prohibición de la discriminación y derechos reconocidos en el Capítulo II) podrán ser objeto de recurso ante la jurisdicción correspondiente, de acuerdo con los procedimientos que establezcan las leyes procesales del Estado». Los principios rectores (art. 40) «podrán ser alegados ante los jueces y tribunales de acuerdo con lo que dispongan las leyes que los desarrollen».

22 «Los dictámenes del Consejo de Garantías Estatutarias tienen carácter vinculante con relación a los proyectos de ley y las proposiciones de ley del Parlamento que desarrollen o afecten a derechos reconocidos por el presente Estatuto».

23 Sobre las garantías de los derechos en el Estatuto andaluz, y sobre los derechos reconocidos en el mismo en general, puede verse M. J. AGUDO ZAMORA, «Derechos sociales, deberes y políticas públicas», en S. Muñoz Machado y M. Rebollo Puig (dirs.), Comentarios al Estatuto de Autonomía para Andalucía, Cizur Menor, Thomson-Civitas, 2008, pp. 263 y ss., en especial sobre las garantías, pp. 299 y ss. También F. BALAguer Callejón (coord.), El nuevo Estatuto de Andalucía, Madrid, Tecnos, 2007, pp. 23 y ss. En clave defensora de la incorporación de derechos C. RuIz-Rico Ruiz, Los derechos en la reforma estatutaria andaluza: realidad compleja y proyección jurídica, Jaén, Universidad de Jaén, 2008. 
Al legislador, y al resto de los poderes públicos, tampoco se les da pequeño papel, pues estarán vinculados por los derechos, y «el Parlamento aprobará las correspondientes leyes de desarrollo, que respetarán, en todo caso, el contenido de los mismos establecido por el Estatuto y determinarán las prestaciones y servicios vinculados, en su caso, al ejercicio de estos derechos» (art. 38). El reconocimiento y protección de los principios rectores «informará las normas legales y reglamentarias [...] la práctica judicial y la actuación de los poderes públicos». Además, éstos «adoptarán las medidas necesarias para el efectivo cumplimiento de estos principios, en su caso, mediante el impulso de la legislación pertinente, la garantía de una financiación suficiente y la eficacia y eficiencia de las actuaciones administrativas» (art. 40).

Siempre nos quedan las garantías extrajudiciales, como el Defensor del Pueblo estatal o autonómico ${ }^{24}$, con sus poderes de mediación muchas veces infravalorados, pero lo cierto es que el panorama general de la posible efectividad de los derechos sociales reconocidos en los Estatutos es más bien pobre, sobre todo si los jueces, habitualmente reticentes en general a favorecer interpretaciones arriesgadas del ordenamiento, se suman, como probablemente suceda, y debe suceder (art. 5 LPOJ), a la manera de ver las cosas del Tribunal Constitucional.

\section{CONCLUSIÓN}

Parece llegado el momento de extraer conclusiones - ya me he extendido bastante siquiera apuntando muchos de los problemas- y creo que éstas podrían ser las siguientes.

La primera, y principal, resaltar el importantísimo papel que representan las Comunidades Autónomas en España en el terreno de los derechos sociales. Esto se puede decir hoy en día de todas ellas, y no sólo de las que han reformado sus Estatutos últimamente introduciendo declaraciones de derechos.

Es de destacar que estas últimas Comunidades proyectan sus competencias sobre un porcentaje muy alto del territorio y la población española. Hay que subrayar, sin embargo, que en las que tienen todavía Estatutos

${ }^{24} \mathrm{Vid}$., por ejemplo, el art. 41 de mismo Estatuto andaluz, que dispone que «corresponde al Defensor o Defensora del Pueblo andaluz velar por la defensa de los derechos enunciados en el presente Título». 
«antiguos», también las políticas sociales son fundamentalmente autonómicas, de manera que esto es algo que se puede predicar de España en su conjunto.

La segunda conclusión es que la incorporación a determinados Estatutos de derechos sociales, tanto como intentos de nuevos derechos subjetivos, como con forma de principios o mandatos, plantea infinidad de problemas, algunos de los cuales hemos apuntado en la exposición anterior. Ante esta situación cabe preguntarse si se ha conseguido un resultado verdaderamente significativo o si hemos caído en la ingenua, y habitual, composición de lugar de los malos juristas, que consideran que para resolver un problema - en este caso el de la plena vigencia de las políticas sociales- basta con una pomposa y pretenciosa declaración de tipo normativo y del máximo nivel posible.

Pocas leyes, pero buenas, era el ideal de la Ilustración. Aquí se plantea el dilema clásico del constitucionalismo de qué es lo que hay que dejar que regulen las generaciones vivas. Creo que la experiencia ha demostrado ampliamente los límites taumatúrgicos del Derecho y que las declaraciones enfáticas y rimbombantes pueden tener un efecto propagandístico evidente, pero hacen poco para resolver los problemas de los ciudadanos, que es a lo que deberíamos dedicarnos preferentemente los leguleyos. 